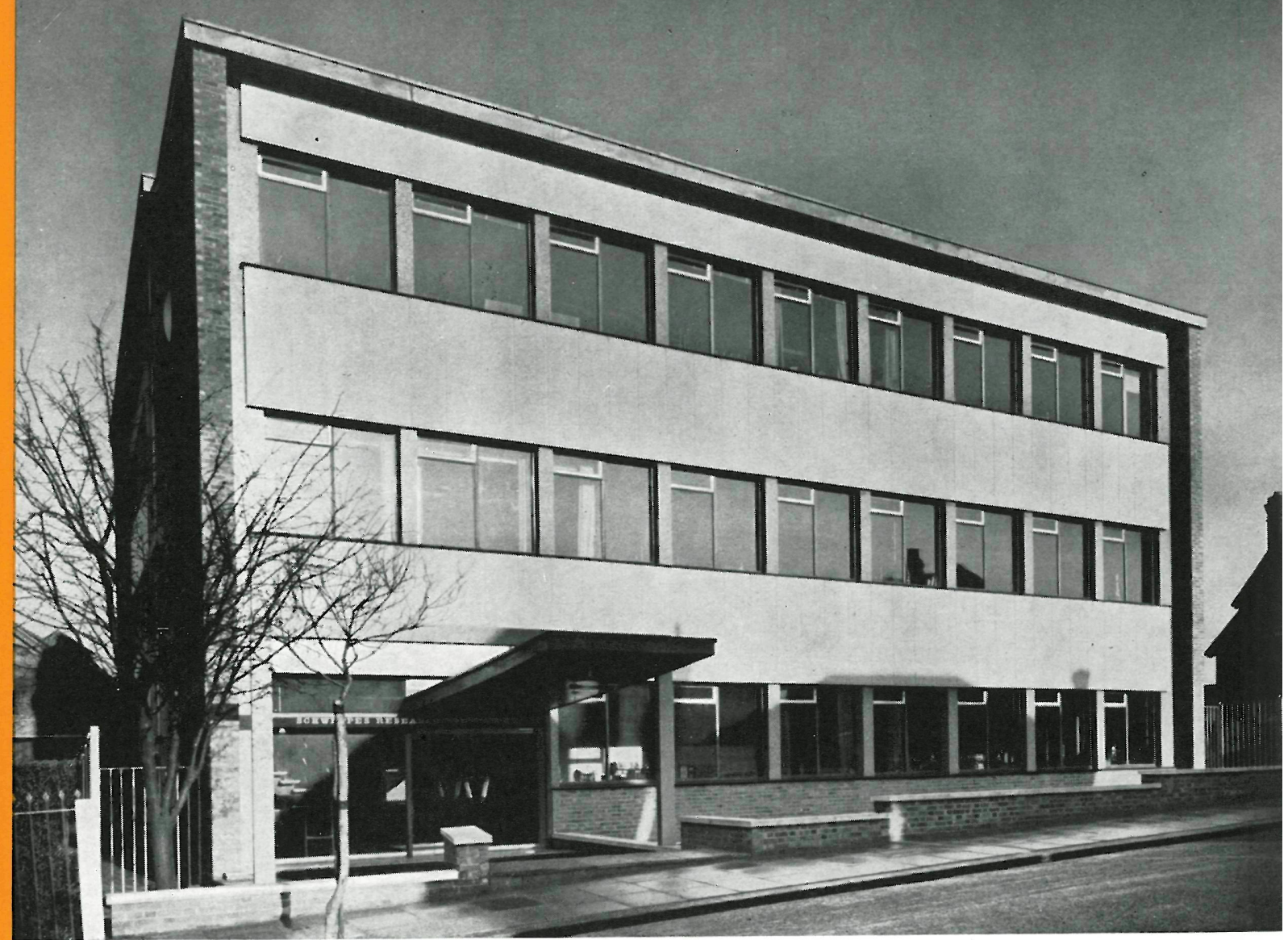

$133 \cdot 9$

\title{
nuevo laboratorio, en Londres
}

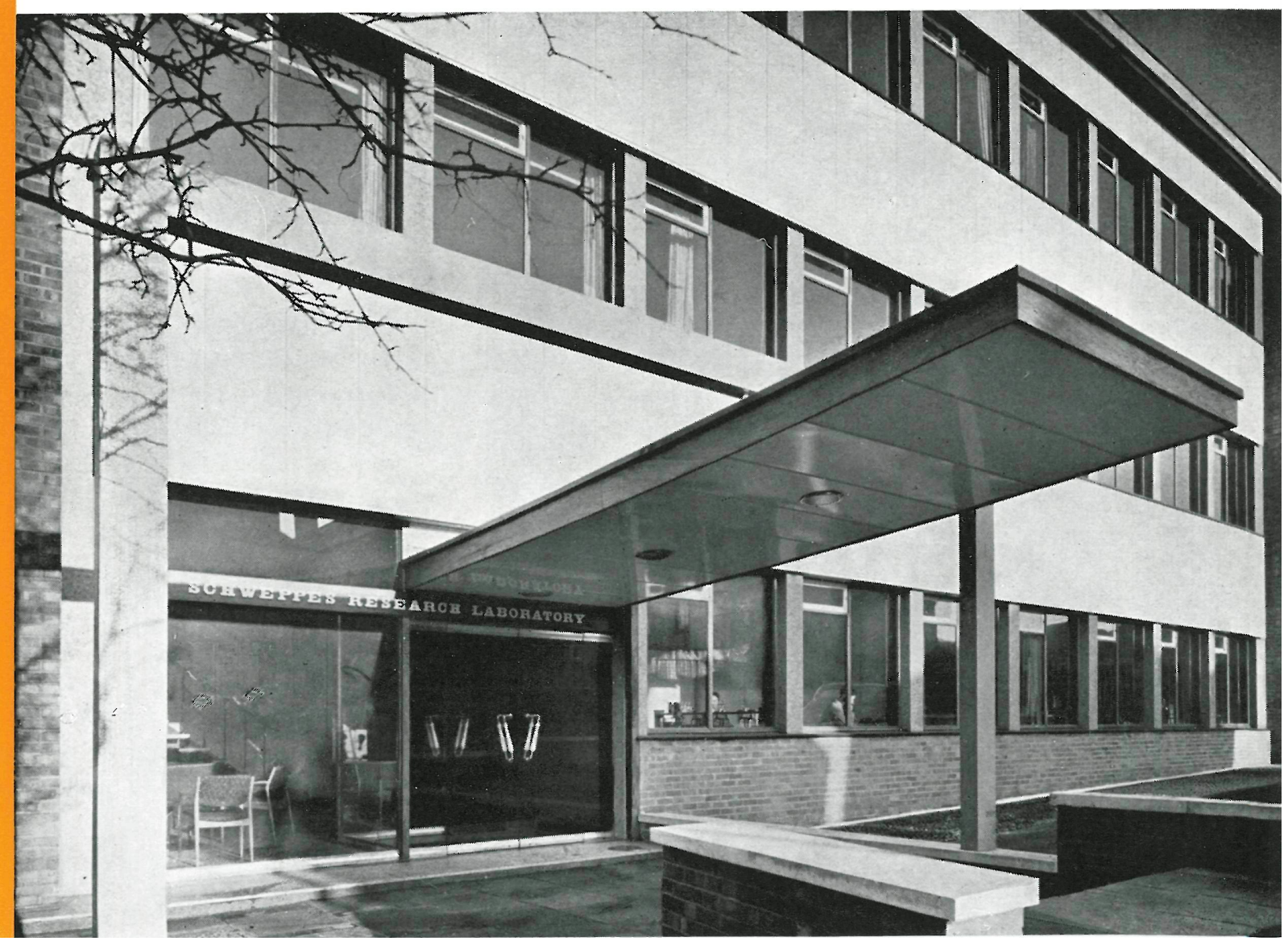



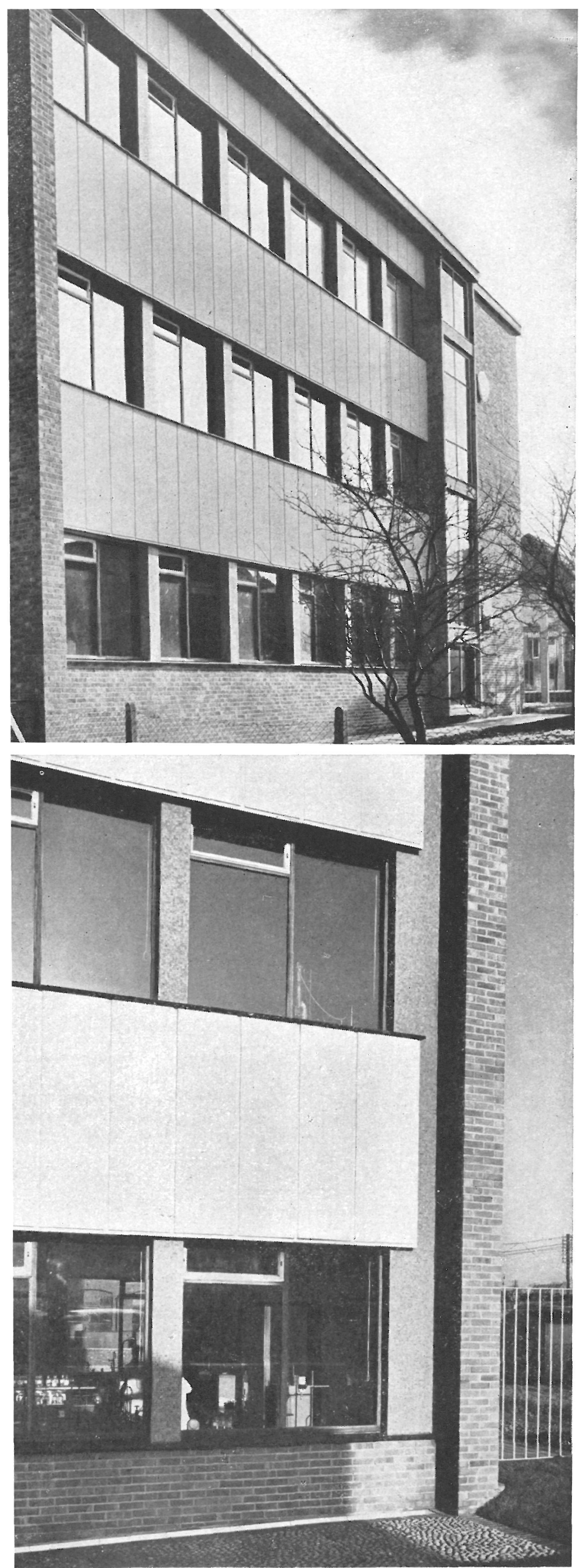

El aumento en $\epsilon \mathrm{l}$ consumo de bebidas sin alcohol y zumos de frutas ha sido muy notable en estos últimos años, lo cual ha obligado a desarrollar una serie de trabajos de investigación del sabor, química y tratamiento del agua, microbiología, sistema de envase, etc.

La Sociedad Limitada Schweppes ha reconocido la importancia de un control e investigación de la calidad de sus productos, estando todas sus fábricas provistas de laboratorios con personal químico especializado. Hasta ahora, las funciones de investigación se habían dividido en diversas secciones; pero con este nuevo laboratorio, único en Europa, se facilita la concentración de ensayos que realiza esta Organización conocida en todo el mundo.

La decisión de construir este Laboratorio Central fué tomada en $\epsilon \mathrm{l}$ año 1953, y se eligió un solar, de dimensiones reducidas, en las afueras de Londres, próximo a la fábrica Hendon de dicha Sociedad.

Dadas las necesidades del programa y la superficie disponible, se proyectó el edificio en tres plantas. Toda la tabiquería puede modificarse en un momento dado, con objeto de adaptarse fácilmente a otra nueva distribución que exija la serie de ensayos a realizar en cada momento. Por ello, se ha conservado la flexibilidad de sus tres plantas instalando todos los servicios en el sótano.

En la planta baja se encuentra la sección de productos de frutas y un amplio espacio, ocupado por la sala piloto, el cual alberga equipos comerciales a escala reducida. En la planta primera se investigan los productos, y está provista de dos laboratorios perfectamente equipados. Y en la última planta se hallan las secciones de análisis y microbiología, y está dotada de una sala de prueba y la sala de inoculación, aparte de una pequeña superficie de almacenaje.

La estructura del edificio es de acero, adaptada al módulo de la planta de 1,22 m. Cuando la estructura queda vista, se protege contra el fuego con amianto. 

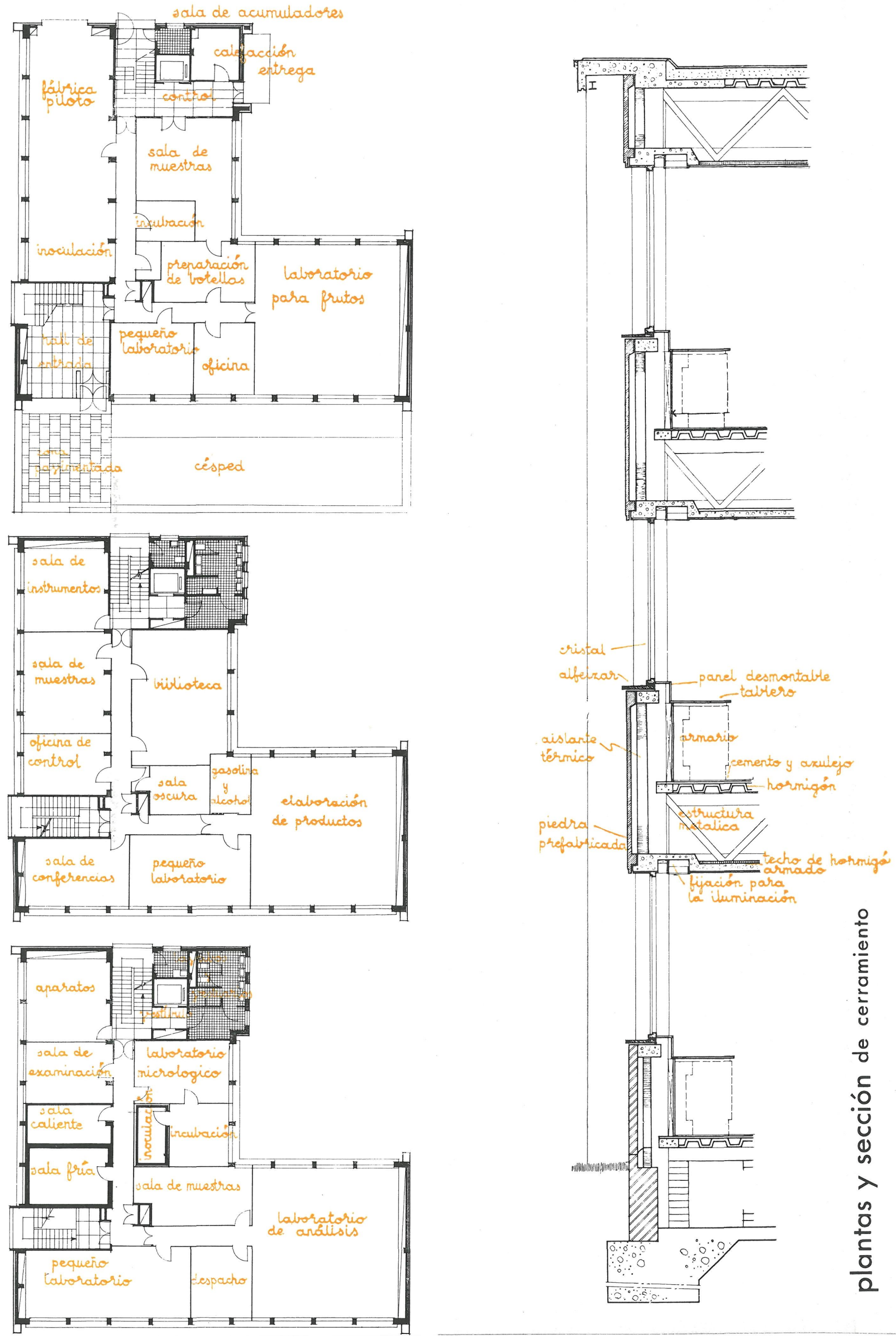

(C) Consejo Superior de Investigaciones Científicas Licencia Creative Commons 3.0 España (CC-by) 


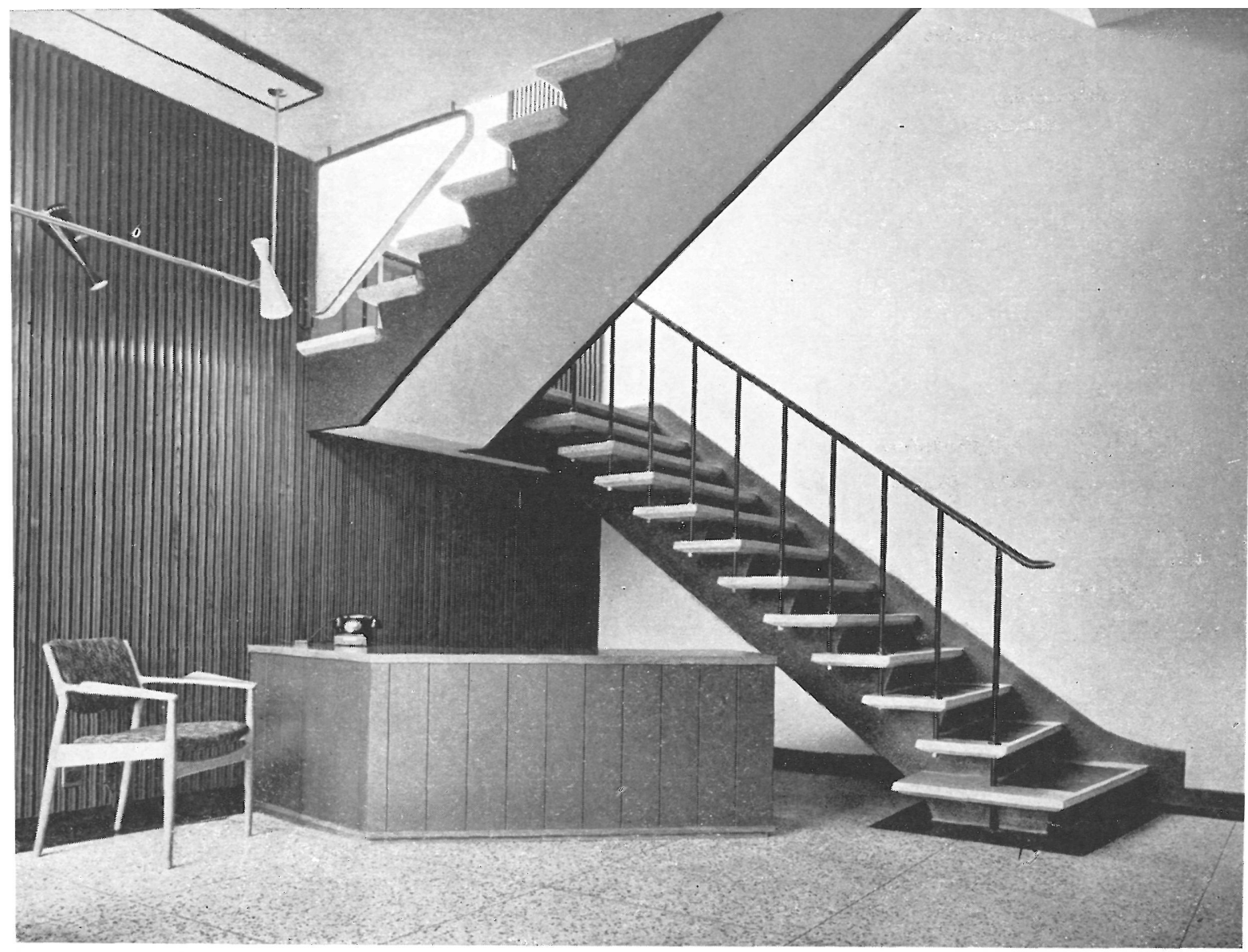

La calefacción se ha realizado con paneles de techo, y el sistema de ventilación permite renovar el aire cinco veces por hora; el aire caliente entra por los paneles de techo y sale por las rejillas situadas en los zócalos, las cuales corren a lo largo de todo el perímetro del edificio.

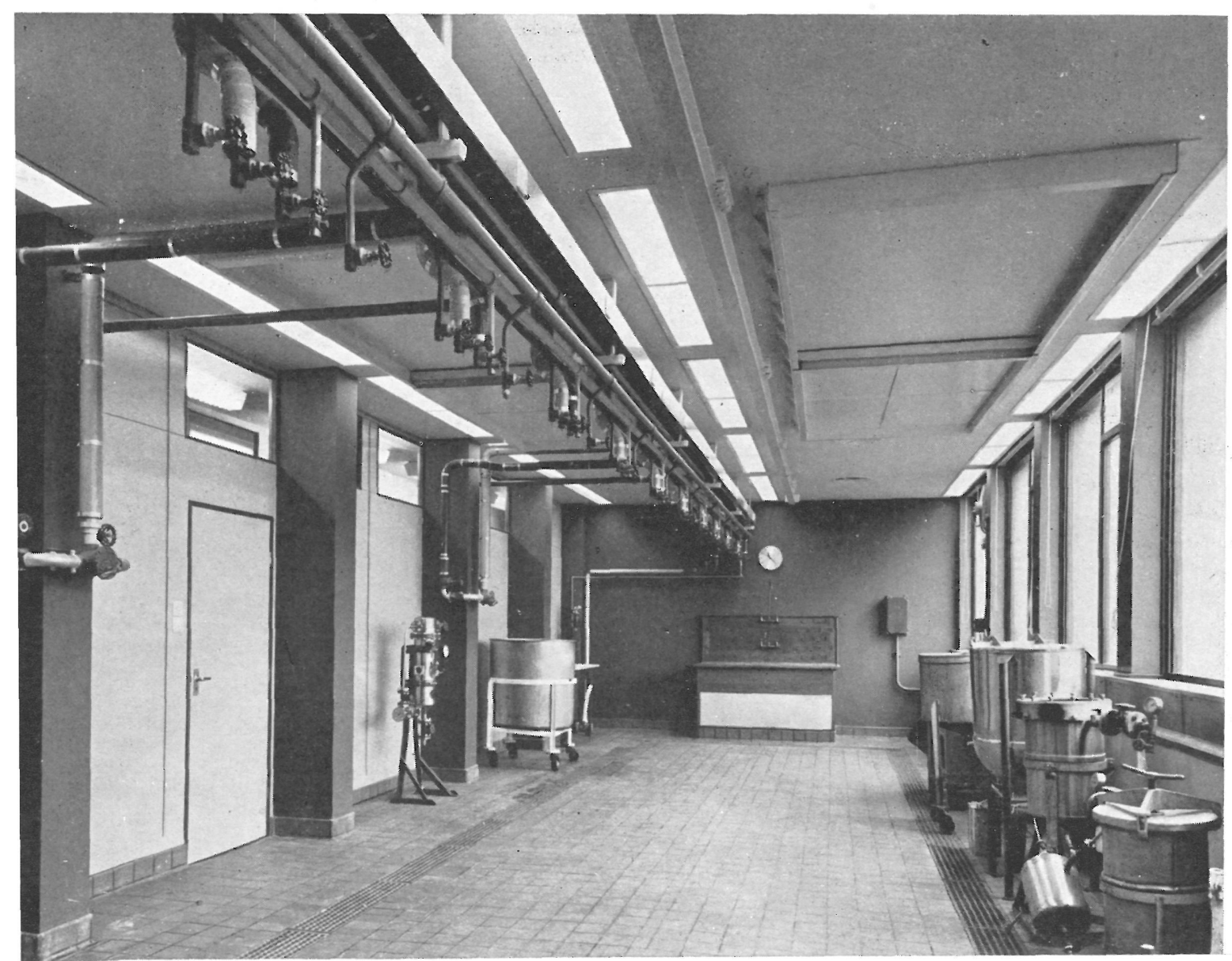

Fotos:

SYDNEY W. NEWBERY 